\title{
Design and Calculation of Hydraulic System for Full Hydraulic Drive Paddy Field Transplanter
}

\author{
Xiao Ruan 1. 2. a, Weiguo Zhu' ${ }^{1 . b}$,Chi Zhang 1.2.c
}

${ }^{1}$ School of Mechanical and Material Engineering, Huaiyin Institute of Technology, Huaian 223003, China;

2School of Mechanical and Power Engineering, Nanjing Tech University, Nanjing 211800, China

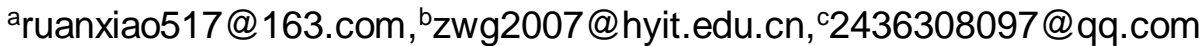

Keywords: Paddy field transplanter, Hydraulic drive, Design calculation.

\begin{abstract}
The full hydraulic drive paddy field transplanter is a new paddy field work machine, which consists of power system, hydraulic transmission system, frame, steering system, walking mechanism and other key components. Based on the design scheme of the hydraulic system of paddy field transplanter, the main components of the hydraulic system are designed and calculated.
\end{abstract}

\section{Introduction}

In recent years, with the high income of rice cultivation, rice cultivation in three provinces in northeastern China has expanded rapidly. However, the per capita land area of northern China, artificial transplanting, transporting seedlings delay farming, reduce production. Therefore, the rice transplanter and supporting the transplanter's demand is very large, but the domestic development and utilization of paddy field transplanter have not yet keep up with the technology, this technology is very important for manufacturers to capture the market. Based on this, the research group carried out the relevant aspects of the study, and design and development of a full hydraulic drive paddy field transplanter.

Hydraulic paddy field transplanter mainly by the power system, hydraulic drive system, control devices, frame and walking device, electronic control system and other components[1]. Power system is the vehicle's power source, the main engine components. Hydraulic system consists of hydraulic pump, control valve, hydraulic cylinder, hydraulic motor, pipeline, fuel tank and other components, to achieve the power transmission and a variety of vehicle manipulation. The frame is the whole transplanter base. The vast majority of components and assembly are fixed through the frame to its location. Hydraulic system design shown in Figure 1, mainly divided into two parts of the drive and steering.

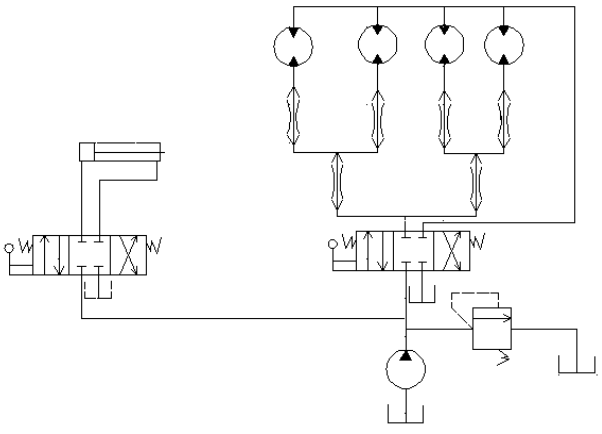

Fig.1 Hydraulic system design

\section{Design Principles and Main Contents of Hydraulic System of Paddy Field Transplanter}

\subsection{Design Principles}

Full hydraulic drive paddy field rice transplanter design must follow the following principles: 
(1)To meet the requirements of use;to meet the requirements of the economy ;to meet the requirements of labor protection;

(2) The paddy field transplanter in the smooth road and muddy paddy fields have a good passability;

(3) The size of the walking device of the transplanter should meet the requirements of road transport

(4) The performance of each component or assembly should be coordinated, matched, and consistent with the overall performance of the consistency and optimization

\subsection{Hydraulic walking system}

As shown in Figure 1, the hydraulic walking system diagram consists of hydraulic pumps, hydraulic motors, hydraulic cylinders, control valves and other components. The hydraulic oil is pumped from the tank by the hydraulic pump and returned to the tank through the relief valve. The relief valve can keep the pressure of the hydraulic system constant and realize the stability of the hydraulic system and limit the system pressure through the overflow of the oil. Through the three-position four-way manual valve, synchronous valve, drive the motor drive wheel rotation. Synchronous valve is the speed of synchronization, that is, when the four motors were subjected to different load, the synchronization valve through the internal pressure and flow-sensitive components automatically adjust to keep the cylinder movement synchronization.

Three-position four-way manual change-over valve in the transmission system changes the direction of hydraulic oil flow to realize the change of running state. When in the middle position, the chassis is in the parked state; when it is at the left position, the chassis is in the advanced state; when it is in the right position, the chassis is in a retracted state.

\subsection{Hydraulic Steering System}

Steering system in the three-position four-way manual valve to change the direction of hydraulic oil to achieve the direction of change. One end of the hydraulic cylinder is connected with the frame and the other end is connected with the wheel. When the valve is in the neutral position, the direction of travel is the same; when it is at the left position, it turns to the left; when it is in the right position, it turns to the right.

\section{Calculation of Hydraulic System for Paddy Field Transplanter}

\subsection{Basic Parameters of the Hydraulic Machine of Paddy Field Transplanter}

The design requirement of paddy field transplanter running system : the maximum speed of paddy field transplanter is not more than $3-5 \mathrm{~km} / \mathrm{h}$; the steering mode is deflecting the front wheel[2]; machine weight is $0.5 \mathrm{t}$, carrying is $1.5 \mathrm{t}$, the engine power is $11.03 \mathrm{kw}$; Hydraulic pump system working pressure is $16 \mathrm{MPa}$, the maximum displacement of $150 \mathrm{~mL} / \mathrm{r}$; walking hydraulic motor maximum displacement is $100 \mathrm{~mL} / \mathrm{r}$; hydraulic cylinder maximum displacement is $100 \mathrm{~mL} / \mathrm{r}$.

\subsection{Determination of Hydraulic Actuator Force Of Paddy Field Transplanter}

\subsubsection{Determination of Hydraulic Cylinder Force}

The force acting on the piston of the hydraulic cylinder exists a equilibrium condition:

$$
F_{\text {oc }}+F_{f}-F=0
$$

In the formula: $F_{O C_{-}}$the force acting on the wheel is determined by the steering resistance moment of the steering wheel, $F_{f}$-the friction between the piston and the cylinder, $F$ the thrust of the high pressure oil to the piston. According to the characteristics of paddy field machinery and related information, the $F_{O C}=28883 \mathrm{~N}$, the $F_{f}=2970 \mathrm{~N}$. After calculation the $F=31853 \mathrm{~N}$.

\subsubsection{Determination of the Force of Hydraulic Motor}

The machine must overcome the rolling resistance $F_{f}$ from the ground, the air resistance $F_{w}$ from the air, the ramp resistance $F_{i}$ at the uphill, and the acceleration resistance $F_{j}$ at the time of acceleration. Therefore, the total resistance of the machine in driving is

$$
\sum F=F_{f}+F_{w}+F_{i}+F_{j}
$$


(1) Paddy field transplanter rolling resistance

The rolling resistance can be expressed by the following formula:

$F_{f}=f G_{s} \cos \alpha=1.995 \mathrm{kN}$

In the formula: $f=0.1$ is the rolling resistance coefficient; total weight of equipment $G_{s}=20000 \mathrm{~N}$; movement of the surface of the tilt angle to take $\alpha=4^{\circ}$.

(2) Ramp resistance

The ramp resistance can be expressed as follows:

$F_{i}=G_{s} \sin \alpha=1.395 \mathrm{kN}$

(3) Air resistance

The air resistance can be expressed as follows:

$F_{w}=\frac{C_{D} A U_{a}^{2}}{21.15}=0.073 k N$

In the formula: $C_{D}$ - air resistance coefficient; $A$ - windward area $\left(m^{2}\right) ; U_{a}$ - travel speed.

(4) Accelerate resistance

$F_{j}=\delta m \frac{d u}{d t}=0.0032 \mathrm{kN}$

In the formula: $\delta$ - the vehicle rotation mass conversion factor; $m$ - vehicle quality; $\frac{d u}{d t}$ - driving acceleration.

So the total force of the hydraulic motor, that is, the total resistance of the transplanter:

$\sum F=3.4662 k N$

\subsection{Calculation of Hydraulic Components}

The calculation of hydraulic components includes: cylinder diameter, cylinder wall thickness, piston rod strength, hydraulic cylinder working pressure, hydraulic motor displacement and working pressure, hydraulic cylinder and hydraulic motor displacement [3].

\subsubsection{Inner Diameter of Hydraulic Cylinder}

From the "mechanical design manual" table know:

$D=\sqrt{\frac{4 F}{\pi P}}$

In the formula: $F$ - hydraulic cylinder load; $P$ - system pressure; $D$ - cylinder diameter. By the basic parameters $F=31.853 \mathrm{kN}, P=16 M P a$. Substituting data $D=50.34 \mathrm{~mm}$.

Refer to Hydraulic Cylinder Series Dimensions $\mathrm{D}=63 \mathrm{~mm}$.

\subsubsection{Cylinder Wall Thickness}

Check the "mechanical design manual" know: $\delta_{0}=\frac{P_{\max } * D}{2 *[\sigma]}$

In the formula: $P_{\max }$ - the maximum working pressure in the cylinder ( $\mathrm{MPa}$ ); $\left.\sigma \sigma\right]$ - cylinder material allowable stress $\left(\mathrm{N} / \mathrm{mm}^{2}\right)$.Substituting data $\delta_{0}=24 \mathrm{~mm}$.

By $D_{1}: \delta_{0} \leq 20$, Check "mechanical design manual" to know the hydraulic cylinder diameter:

$D_{1}=88 \mathrm{~mm}$.

\subsubsection{Cylinder Wall Thickness Checking}

Rated working pressure should be lower than a certain limit to ensure working safety: $P_{n} \leq \frac{0.35 * \sigma_{s}\left(D_{1}^{2}-D^{2}\right)}{D_{1}}$,Election materials $2 \mathrm{G} 330-450, \sigma_{S}=330 \mathrm{~N} / \mathrm{mm}^{2}$.

By the calculated $P_{n}=14.95 \mathrm{MPa}$, The working pressure of the selected system is $16 \mathrm{Mpa}$, the requirements is can be satisfy.

\subsubsection{Piston Rod Calculation}




$$
d=D \sqrt{\frac{\vartheta-1}{\vartheta}}
$$

The ratio is determined by the "Mechanical Design Manual" table is $\vartheta=2$, Then by the table $\mathrm{d}=35 \mathrm{~mm}$.

\subsubsection{Piston Rod Strength Calculation}

$$
\sigma=\frac{P * 4 * 10^{-6}}{\pi * d^{2}}=105.4 \mathrm{~N} / \mathrm{mm}^{2}
$$

In the formula : $P$ - piston rod force $(\mathrm{N}) ; d$ - piston rod diameter $(\mathrm{m})$. Allowable stress values are $[\sigma]=100 \sim 110 \mathrm{~N} / \mathrm{mm}^{2}$. The requirement can be satisfy.

\subsubsection{Identifying Working Pressure of Hydraulic System}

In the case of not considering energy losses, the power of system to:

$\mathrm{P}=\mathrm{pQ} \times 10^{-3}$

In the formula: $\mathrm{p}$ - Hydraulic pump outlet pressure $(\mathrm{Pa})$; $\mathrm{Q}-$ Hydraulic pump output flow $\left(\mathrm{m}^{3} / \mathrm{s}\right)$

It can be seen from the above formula, when the system transfer power is certain, improving the system's working pressure can reduce the system flow which through the hydraulic components, then reducing the corresponding hydraulic components and the entire hydraulic system structure size and quality. Therefore engineering and agricultural hydraulic transmission are using high pressure systems. According to the working pressure of the hydraulic system of the above: $P=16 M P a$

\subsubsection{Determine the Main Parameters of Hydraulic Cylinder and Working Pressure}

The effective working pressure of the hydraulic cylinder is the part of the pressure required by the hydraulic cylinder to overcome the external load.The numerical value is:

$$
p_{g}=p_{b}-\Sigma \Delta p_{j}-p_{h} \times \frac{A_{h}}{A_{j}}
$$

In the formula: $p_{b}$-Hydraulic pump outlet pressure ( $\mathrm{MPa}$ ); $\sum \Delta p_{j}$-Pipe pressure $\operatorname{loss}(\mathrm{MPa}) ; p_{h}-$ Oil back pressure( $\left.\mathrm{MPa}\right) ; A_{j}, A_{h}$ - Into the oil Chamber and a return oil Chamber of hydraulic cylinder effective work area $\left(m^{2}\right)$

The loss of pressure in the formula above $\Sigma \Delta p_{j}$, Including pressure from hydraulic pump oil exports flow through the pipeline and all kinds of hydraulic components (primarily valve components) when pressure loss.After careful calculations in piping assembly drawing can take place. For preliminary calculations, reference can be made to the empirical data of the same machine, taking $\sum \Delta p_{j}=3 \sim 4 M P a$, then $P_{g}=3 M P_{a}$

\subsubsection{Determine the Hydraulic Motor's Displacement and Pressure}

Hydraulic motor's displacement is known by the given numerical value $q=100 \mathrm{~mL} / r$. Effective work of the hydraulic motor pressure $p_{m}$ is calculated by the following formula:

$$
P_{m}=P_{b}-\sum \Delta P_{j}-P_{k}
$$

The loss of pressure in the formula can be determined by the empirical data described earlier. The numerical value of oil back pressure $p_{h}$ should be chosen according to motor back pressure required $0.5 \mathrm{kN}$,so: $P_{m}=3.4 \mathrm{kN}$

\subsubsection{Calculate the Flow of Hydraulic Cylinders and Hydraulic Motors}

According to the maximum speed and maximum speed to calculate the flow of hydraulic cylinders and hydraulic motors [4].

Hydraulic cylinder required flow: $Q_{\max }=A_{g} v_{\max }=0.00003 \mathrm{~m}^{3} / \mathrm{s}$ 
In the formula: ${ }^{A_{g}}$-The effective work area of hydraulic cylinder $(\mathrm{m} 2) ;{ }^{v_{\max }}$-The maximum speed of the hydraulic cylinder $(\mathrm{m} / \mathrm{s})$.

Required flow of hydraulic motor:

$Q_{\max }=q_{0} w_{\max } \frac{1}{\eta_{v}}=0.00004 m^{3} / s$

In the formula: $q_{0}$-Theory displacement of motor $(\mathrm{mL} / \mathrm{r}) ; w_{\max }$-Motor maximum speed $(\mathrm{rad} / \mathrm{s}) ; \eta_{v}-$ Volume efficiency of motor.

\section{Selection of Hydraulic Components}

\subsection{Choice of Hydraulic Cylinder}

Hydraulic cylinder plays an important role in the whole hydraulic system, it is the beginning of the entire hydraulic system cycle point, According to the above calculation result, choice of hydraulic cylinder is clear. Selecting model for SG-1 hydraulic cylinder, piston rod diameter $35 \mathrm{~mm}$, travel $300 \mathrm{~mm}$, push $49.88 \mathrm{kN}$, pulling $34.48 \mathrm{kN}$.

\subsection{Choice of Hydraulic Pump}

Choosing hydraulic pump according to the working pressure of the hydraulic system (hydraulic pump outlet pressure) to the selected form of hydraulic pump. Choice of hydraulic pump pressure more than $25 \%$ of the system pressure to make sure the hydraulic pump has a pressure reserve. In consider of economic, selecting the hydraulic pump rated pressure of 20Mpa.Selecting model CBG hydraulic pump displacement $16.7 \mathrm{ml} / \mathrm{r}$, pressure is $10 \mathrm{MPa}$, power: $105 \mathrm{~kW}$.

\subsection{Choice of Hydraulic Motors}

According to the calculated hydraulic motor displacement, working pressure and flow, select the hydraulic motor model CMZ732, displacement $100 \mathrm{ml} / \mathrm{r}$, pressure $20 \mathrm{MPa}$, theoretical torque $130 \mathrm{Nm}$, torque $150 \mathrm{r} / \mathrm{min}$.

\section{Summary}

The design has been applied to the prototype, it has been achieved accurate vehicle operation, safe and stable operation. Fully hydraulic drive transport seedlings in paddy field will greatly improve the efficiency of rice transplanter, significantly lower labor and production costs. Paddy field transplanter mechanization of agricultural production is an innovation, it is benefit to affect and improve the level of mechanization in the field. The promotion of paddy field transplanter is conducive to the liberation and development of productive forces, so that the rural surplus labor force to the city or the second and tertiary industries to promote and promote China's industrialization and urbanization.

\section{References}

[1]. Wen chunbang. Mechanical Design Manual. Beijing:China machine press,2010

[2]. Chinese Academy of agricultural mechanization Sciences series.Agricultural machinery design manual. Beijing: Chinese Academy of agricultural science and technology press,2007

[3]. Dong Weiliang. Hydraulic Design Manual.Beijing: China machine press,2005

[4]. Wang wangyu. Automatic design.Beijing :China machine press, 2011 